\title{
Historical Item
}

Seventh International Hot Atom Chemistry Symposium ( $7^{\text {th }}$ IHACS), Jülich, Germany, September 1973.

Photograph taken during one of the sessions. It shows in the first row (from left to right); sitting, F. Sherwood Rowland and Alfred P. Wolf; standing, Gerhard L. Stöcklin, the Symposium Chairman.

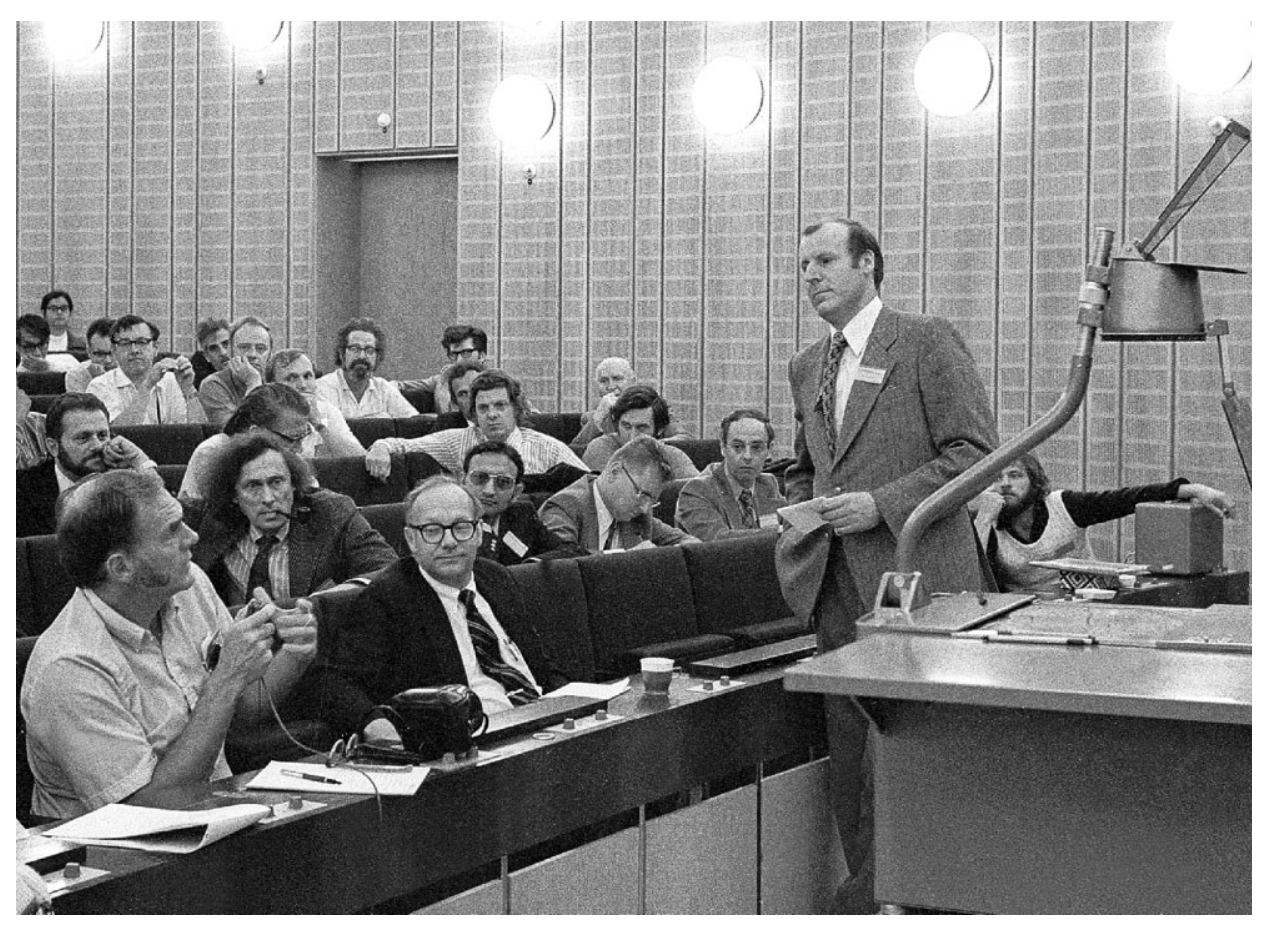

Courtesy: Forschungszentrum Jülich, Germany

F. Sherwood Rowland (Nobel Prize, 1995) contributed many articles to Radiochimica Acta. Alfred P. Wolf and Gerhard L. Stöcklin served as Editors of the Journal from 1977 to 1995. 